\title{
A eutanásia, à luz da DUBDH, no mundo e no Brasil
}

\section{Euthanasia, in the light of the UDBHR, around the world and in Brazil}

\author{
Danilo Coelho Alves de Sousa \\ Presidência da República, Brasília, Brasil \\ danilo@danilo.med.br \\ Priscila Oliveira de Carvalho \\ HUB, Brasília, Brasil \\ priscila.ucb@gmail.com \\ Paula Pires Souza de Oliveira \\ Universidade de Brasília, Brasília, Brasil \\ paulapsdeoliveira@gmail.com \\ Camilo Hernan Manchola Castillo \\ Cátedra Unesco / Programa de Pós-Graduação em Bioética da UnB, Brasília, \\ Brasil \\ camilomanchola@gmail.com

\section{Volnei Garrafa} \\ Cátedra Unesco / Programa de Pós-Graduação em Bioética da UnB, Brasília, \\ Brasil \\ garrafavolnei@gmail.com
}

Resumo: A eutanásia pode ser entendida como o ato, praticado por um terceiro, que põe intencionalmente fim à vida de uma pessoa sob demanda desta. Este documento analisa algumas legislações internacionais a respeito, à luz da Declaração Universal sobre Bioética e Direitos Humanos da Unesco. O referido documento serviu de base para muitos países europeus regular diferentes formas de eutanásia. Encontrou-se que a legislação belga, promulgada em 2002, não fere o disposto na Declaração e que não há, no Brasil, normativa específica que regulamente a eutanásia, além de que, iniciativas neste tema não avançam no parlamento nacional. É importante que as regulamentações do assunto se adequem à realidade de cada país, mas evitando que a visão moral majoritária sobre o assunto se imponha sobre a moralidade de uma minoria vulnerável. A criação de um Conselho Nacional de Bioética no Brasil seria importante passo para apoio à regulamentação da questão.

Palavras-chave: bioética, eutanásia, cuidados paliativos, terminalidade da vida. 
Abstract: Euthanasia can be understood as the act, practiced by a third party, of intentionally ending the life of a person upon his/her request. This document analyzes some legislation on euthanasia around the word, in the light of the UNESCO Universal Declaration on Bioethics and Human Rights. It was documented that only four European countries have regulated some form of euthanasia. The Belgian legislation, enacted in 2002, does not violate the provisions of the Declaration. There are not, in Brazil, specific rules governing euthanasia, and initiatives in this area do not advance in Parliament. It is important these regulations to be related to the reality of each country, but preventing the main morality to be imposed on the morality of a vulnerable minority. The creation of a National Council on Bioethics in Brazil would be an important step to regulate such issues.

Keywords: bioethics, euthanasia, palliative care, terminality of life.

\section{Introdução}

Definir os termos associados à questão da terminalidade da vida é um problema dos mais difíceis, porque muitos deles não proporcionam definições precisas. A distinção entre matar e deixar morrer, muito usada para distinguir a eutanásia ativa da eutanásia passiva, é difícil de ser aplicada às questões médicas cotidianas. Desligar a bomba de infusão de um medicamento que mantém a pressão sanguínea de um paciente artificialmente normalizada - mantendo, por conseguinte, sua vida artificialmente - por exemplo, pode ser considerado, tanto "um ato de deixar morrer" quanto uma postura ativa de abreviar a vida de alguém.

Entretanto, a delicada tarefa de definir as terminologias, em muitos casos, pode não ser tão importante para o debate ético sobre a eutanásia. A classificação, por exemplo, do ato descrito acima como eutanásia ativa ou passiva é secundário para o debate ético, uma vez que "não há diferença moral relevante entre matar e deixar morrer" (p.92) (1).

Neste sentido, delimitaremos o conceito de eutanásia com base na legislação dos três países em que este procedimento foi regulamentado - Bélgica, Holanda e Luxemburgo - uma vez que a proposta do presente estudo é subsidiar o debate da eutanásia com vistas a proporcionar avanços na normativa vigente no Brasil sobre a terminalidade da vida. $\mathrm{O}$ artigo $\mathrm{n}^{\circ} 2$ da lei belga diz "Há de se entender 
a eutanásia como o ato, praticado por um terceiro, que põe intencionalmente fim à vida de uma pessoa sob demanda desta" (tradução livre) (2). O artigo terceiro da lei da eutanásia belga, datada de 2002 (2), restringia a abreviação da vida apenas a pacientes maiores ou emancipados e capazes, com doença grave e incurável, de sofrimento físico ou psíquico constante e insuportável. Mas a lei sofreu alteração em fevereiro de 2014 (3), para permitir a eutanásia em menores, sem restrição de idade, quando acometidos exclusivamente por sofrimento físico. Os menores precisam ter discernimento da sua decisão atestado por um médico ou psicólogo, além da concordância dos pais. No mesmo artigo, o ato da eutanásia é definido como um ato a ser executado apenas por médicos.

A legislação da Holanda (4), que foi o primeiro país a legalizar o procedimento, não cita o termo "eutanásia", mas o substitui por "cessação da vida". As condições exigidas são muito parecidas às belgas, apesar de abranger a possibilidade de menores acima de 12 anos solicitarem a eutanásia, desde que capazes e em concordância com a opinião dos responsáveis. Luxemburgo (5), por sua vez, o último país a legalizar a eutanásia, em março de 2009, traz a mesma definição da Bélgica.

Este trabalho estará subdividido nas seguintes partes. Primeiro, serão tratados os aspectos gerais das normativas específicas sobre a eutanásia vigentes no mundo. Segundo, será abordada a normatização sobre a eutanásia no Brasil, inclusive projetos de lei sobre o tema. Terceiro, serão analisadas a primeira e segunda seção, à luz dos artigos 3, 5, 6 e 8 da Declaração Universal sobre Bioética e Direitos Humanos da UNESCO que tratam, respectivamente de: Dignidade Humana e Direitos Humanos; Autonomia e Responsabilidade Individual; Consentimento; Respeito pela Vulnerabilidade Humana e pela Integridade Individual. Finalmente, serão apresentadas algumas considerações finais. 


\section{Eutanásia no mundo}

São pouquíssimos os ordenamentos jurídicos que legalizaram algum modo de abreviação da vida nas situações de sofrimento extremo. Há apenas quatro países, todos europeus, que regulamentaram algum tipo de eutanásia ativa ou suicídio assistido: Holanda, Bélgica, Suíça e Luxemburgo. Ressalte-se que o estado do Oregon, nos Estados Unidos, também o fez. Vale ressaltar que as leis desse país permitem que decisões sobre certos temas fiquem a nível estadual. A própria definição de eutanásia varia nestes locais, o que demonstra a necessidade de a legislação regulamentar o que cada país entende pelo termo. Não há consenso sobre a definição da eutanásia e de suas classificações.

Vale a pena registrar uma situação específica que aconteceu no Reino Unido, em que houve quatro tentativas frustradas de aprovar algum tipo de legalização da eutanásia ou de suicídio assistido, entre 2003 e 2006, fato que remete às dificuldades que envolvem o debate sobre o direito à morte em casos extremos de sofrimento mesmo em países supostamente com alto grau de laicidade no legislativo (1).

As formas legalizadas de eutanásia ou suicídio assistido variam nos países supracitados, bem como a data em que tal normatização foi aprovada pelos respectivos parlamentos. Na Holanda, a mudança se deu inicialmente por jurisprudência, sem amparo de lei específica sobre o tema. Desde 1973 a justiça holandesa aceitava a eutanásia praticada por médicos, quando a morte era necessária para prevenir o sofrimento. Era compreensão do judiciário local que o dever de preservar a vida pudesse ser superado, em alguns casos, pelo dever de prevenir o sofrimento (6). Todavia, a falta de regulamentação do tema trazia incertezas para a classe médica e para os pacientes, de modo que foi necessária a aprovação, em abril de 2002, de uma Lei de Terminalidade da Vida e Suicídio Assistido. Nesta lei, foi regulamentada tanto a eutanásia quanto o suicídio assistido (4).

A Bélgica, por sua vez, em maio de 2002, menos de dois meses depois de aprovada a regulamentação holandesa, legalizou a eu- 
tanásia, mas não o suicídio assitido. Como dito acima, em 2014 o país ampliou a abrangência da lei de 2002, sendo o primeiro país a eliminar o limite de idade para eutanásia (3). Ao contrário, a Suíça, em seu Código Penal, criminaliza qualquer tipo de eutanásia, mas permite o suicídio assistido, apenas em casos em que o motivo seja "inteiramente honorável"; por exemplo, para abreviar o sofrimento de doentes terminais (7).

A regulamentação de Luxemburgo (5), realizada em 2009, trouxe aspectos da lei holandesa, como a legalização expressa do suicídio assistido, e da lei belga de 2002 (2), como o impedimento da eutanásia em adolescentes a partir de 12 anos - o que é permitido na Holanda (4) -, desde que atendidos pré-requisitos como a concordância dos pais e ratificação da capacidade de o adolescente entender a situação médica em tela.

Nos três países $(2,4,5)$, a decisão não pode ser ratificada por um único médico, mas por, no mínimo, um segundo médico independente. Além disso, os casos autorizados nos três países passarão por comissões de controle e avaliação, que podem ser nacionais (caso da Bélgica e Luxemburgo) ou regionais (caso da Holanda), compostas, no mínimo, por médicos e juristas e, no caso de Luxemburgo, ainda por membros de organizações de classe da área de saúde e por representantes de organizações de defesa dos direitos dos pacientes.

O estado do Oregon (8), por fim, ratificou a Lei da Morte com Dignidade, em 1997, legalizando apenas o suicídio assistido.

Em suma, houve legalização da eutanásia na Holanda, Bélgica e Luxemburgo (3-5), reeditando a tríade do pioneiro bloco econômico BENELUX. E houve legalização do suicídio assistido expressamente na Holanda, Luxemburgo, Suíça e no estado do Oregon (4-8).

Para entendermos a dimensão da eutanásia na Bélgica, é importante considerar que cerca de $1 \%$ das mortes no país se devem ao procedimento. O crescimento anual de eutanásias superou 25\% nos dois últimos anos. Em 2013, foram 1807 casos - 73\% com diagnóstico de câncer -, o que representa alta de 27\% sobre as 1432 eutanásias de 2012. Estima-se que 2 a 3 menores deverão solicitar a eutanásia anualmente neste país (9). 
A primeira legislação belga sobre o tema foi promulgada em 26 de maio de 2002 (2) e está vigente desde setembro do mesmo ano, em decisão tomada a partir do Comitê Nacional de Bioética do país, abordando principalmente sobre a prática da eutanásia ativa. A permissão para realização de um procedimento de eutanásia é concedida para maiores de 18 anos ou maiores de 16 anos emancipados, com capacidade e consciência plena do pedido, feito de forma voluntária, sem nenhuma pressão externa, com paciente em condição médica terminal e com sofrimento iminente.

O paciente tem garantido o direito à informação, devendo ser informado por seu médico sobre sua condição clínica e expectativa de vida, discutindo de forma bilateral o pedido voluntário de realizar um procedimento de eutanásia. A solicitação feita pelo paciente deve ser por escrito, com documento preparado, datado e assinado pelo mesmo. Em casos de situação inviável para tal, um adulto escolhido por ele deve ser o detentor de tal função, não podendo de nenhuma forma ter qualquer benefício financeiro com a morte deste. Para proteger o indivíduo em situação de incapacidade de expressar sua autonomia, a norma belga permite que o indivíduo faça uma declaração antecipada, ratificando sua vontade de que seu médico realize um procedimento de eutanásia, caso passe a sofrer de uma condição acidental ou patológica grave ou incurável, esteja inconsciente e tal condição de saúde não tenha perspectiva de melhora, devendo ser renovada a cada cinco anos, no mínimo.

Com vistas a garantir o adequado cumprimento da Lei sobre Eutanásia, a Bélgica obriga ao médico que realizou o procedimento apresentar relatório padronizado à Comissão Federal de Controle e Avaliação, criada especialmente para avaliar continuamente a aplicação da lei, composta por dezesseis membros, detentores de notório conhecimento e experiência nos assuntos. Oito membros deverão ser médicos; quatro professores universitários; quatro professores universitários de direito; e quatro, outros profissionais de saúde. Cabe também à Comissão se pronunciar sobre casos específicos de solicitações de eutanásia. Para que as decisões da Comissão tenham validade, pelo menos dois terços de seus membros deverão estar presentes (2). 


\section{Eutanásia no Brasil}

Não há, no Brasil, normativa específica que regulamente a eutanásia. O inciso III do artigo primeiro da Constituição Federal, reconhece a "dignidade da pessoa humana" como fundamento do Estado Democrático de Direito. O inciso III do artigo quinto também da Constituição da República, expressa que "ninguém será submetido a tortura nem a tratamento desumano ou degradante", além do art. 15 do Código Civil, segundo o qual "ninguém pode ser constrangido a submeter-se, com risco de morte, a tratamento médico ou a intervenção cirúrgica", o que autoriza o paciente a recusar determinados procedimentos médicos. Além disso, há o art. $7^{\circ}$, inciso III, da Lei Orgânica de Saúde, de nº 8.080 de 1990, que reconhece a "preservação da autonomia das pessoas na defesa de sua integridade física e moral" (10-12).

O Código Penal (13), datado de 1940, não tipifica o crime de eutanásia, mas condena qualquer ato que extingue vidas. $\mathrm{O}$ homicídio voluntário, isto é, o auxílio ao suicídio ou o homicídio, mesmo que à pedido ou por "piedade", é considerado crime. Alguns juristas defendem que a eutanásia fere o artigo 121 do Código Penal, que tipifica o crime doloso. Entretanto, haveria previsão de diminuição de pena, se aquele que comete o crime demonstra estar impelido por motivo de relevante valor social ou moral. O parágrafo quarto do artigo 121 do Código Penal estabelece: "Se o agente comete o crime impelido por motivo de relevante valor social ou moral, sob o domínio de violenta emoção, logo em seguida a injustiça provocação da vítima, o juiz pode reduzir a pena de um sexto a um terço" (14).

Preceitua também o artigo 122 do Código Penal que: “2" $(13,15)$. Em 1996, foi proposto no Senado o Projeto de Lei (PL) 125, que pretendia liberar a prática de eutanásia em algumas situações; porém, o Projeto foi arquivado pelos parlamentares (14).

No ano de 2000, por sua vez, foi apresentado o PL do Senado $n^{o} 116$ (16), de 2000, com o objetivo de excluir de ilicitude a prática da ortotanásia, que foi regulamentada alguns anos depois pelo Conselho Federal de Medicina (CFM) (17). A norma pretende 
modificar o artigo 121 do Código Penal (13), ao definir que não constituiria crime deixar de manter a vida de alguém por meio artificial, se previamente atestada, por dois médicos, a morte como iminente e inevitável, e desde que haja consentimento do paciente, ou, em sua impossibilidade, de cônjuge, companheiro, ascendente, descendente ou irmão. Isto não se aplicaria ao não uso de meios terapêuticos ordinários ou de cuidados normais devidos a um doente, com o fim de causar-lhe a morte (16). No caso, em outras palavras, a ortotanásia significa "deixar o paciente morrer na hora certa - hora para nascer, hora para viver, hora para morrer...".

Este Projeto foi inicialmente arquivado em 2005, sem sequer ter sido votado, embora tenha sido exaustivamente discutido na forma de Audiência Pública pela Comissão de Constituição, Justiça e Cidadania do Senado. Todavia, foi desarquivado, em 2007, por meio de petição de 27 Senadores, provavelmente como decorrência da Resolução que o CFM (17) havia aprovado neste sentido no ano anterior (16). Realmente, em 1996 o CFM (17) aprovou a Resolução $\mathrm{n}^{\mathrm{o}} 1.805$, que permite a ortotanásia, ao afirmar que, na fase terminal de enfermidades graves e incuráveis, é permitido ao médico limitar ou suspender procedimentos e tratamentos que prolonguem a vida do doente, garantindo-lhe os cuidados necessários para aliviar os sintomas que levam ao sofrimento, na perspectiva de uma assistência integral, respeitada a vontade do paciente ou de seu representante legal (18).

A Comissão de Constituição, Justiça e Cidadania, após nova audiência pública, realizada em 17 de setembro de 2009, com a participação de bioeticistas, do CFM, do Conselho Nacional de Bispos do Brasil (CNBB) e da Ordem dos Advogados (OAB) entendeu, em caráter terminativo, que a proposição deveria ser acolhida, por constitucionalidade, juridicidade e regimentalidade, encaminhando o Projeto, sem a necessidade de aprovação pelo Plenário do Senado, à Câmara dos Deputados (16). A proposta tramita até hoje no Congresso Nacional como Projeto de Lei ${ }^{\circ} 6715$ de 2009 e aguarda parecer, sem prazo, na Comissão de Constituição, Justiça e de Cidadania (19). 


\section{A eutanálisa à luz da DUBDH}

A legislação dos países que têm aprovado a eutanásia prevê que aqueles pacientes que falecerem devido a procedimentos de eutanásia serão considerados perante qualquer contrato privado de seguros como tendo morte natural (2). Acerca da comparação entre a Declaração Universal sobre Bioética e Direitos Humanos da Unesco (DUBDH) (9) e a Legislação Belga, nota-se uma preocupação desta última em respeitar a autonomia e além de delegar ao paciente a responsabilidade individual para solicitação do procedimento de eutanásia. Esses conceitos estão previstos no Artigo $5^{\circ}$ da Declaração (9), que busca o respeito à autonomia das pessoas acerca da tomada de decisões.

O Artigo $6^{\circ}$ da DUBDH (9) trata do consentimento informado. $\mathrm{O}$ paciente belga tem seu consentimento preservado, inclusive possibilitando a mudança de opinião sempre que lhe convenha. Médicos e pacientes devem disponibilizar ao paciente toda a informação existente sobre o caso, a qualquer tempo. E a Legislação possibilita que o médico peça novas opiniões sobre o prognóstico do paciente e solicite, quando necessário, avaliação do mesmo por um psiquiatra (2). A garantia do direito à informação é mais um destaque de como a legislação belga se adequa a conceitos de consentimento prévio, respeito à dignidade humana, aos direitos humanos, respeito pela vulnerabilidade humana e pela integridade.

Sobre o respeito pela vulnerabilidade humana e integridade pessoal, presentes no Artigo $8^{\circ}$ da DUBDH (9), a legislação belga demonstra preocupação em proteger e preservar o direto do paciente solicitar ou não a realização de eutanásia, respeitando a condição vulnerável em que estes se encontram (2). É notório e esperado que pacientes que solicitem procedimento de eutanásia estejam em situação de extrema vulnerabilidade, com sua integridade pessoal profundamente alterada. A atuação de junta médica, levando em conta o respeito à autonomia dos doentes, facilita um processo que é extremamente delicado.

Neste sentido, a DUBDH (9), em seu Preâmbulo, reforça a associação entre a ética e os direitos humanos, levando em 
consideração a necessidade de respeito pela dignidade humana, pelos direitos humanos e pelas liberdades fundamentais de cada um. Neste sentido, um paciente que padeça de sofrimento insuportável, com a dignidade afetada, sem permissão e meios adequados para abreviação de sua vida, estaria sofrendo um arbítrio do Estado contrariamente ao seu direito de exercer a autonomia. Seria, portanto um desrespeito aos direitos humanos do paciente terminal que deseja findar o sofrimento insuportável, independentemente se este procedimento é ou não aprovado e aceito por toda a sociedade.

Considerar que um vulnerável tem direito a cessar um sofrimento por meio da eutanásia ou do suicídio assistido, ao se analisar a legislação belga versus a DUBDH, é aceitável, na medida em que as premissas previstas nesta legislação estão condizentes com os parâmetros éticos dos Artigos $3^{\circ}, 5^{\circ}, 6^{\circ}$ e $8^{\circ}$ da Declaração, garantindo, respectivamente, respeito à autonomia, aos direitos humanos, à dignidade humana, à responsabilidade individual, ao consentimento individual e coletivo, à vulnerabilidade humana e integridade pessoal.

Evidencia-se, assim, que a incorporação de novos referenciais teóricos à bioética, além dos quatro princípios tradicionais de respeito à autonomia, beneficência, não-maleficência e justiça, resultam na possibilidade de novos enfoques para a discussão de temas bioéticos (21). A prática bioética comprometida com os mais vulneráveis, considerando conceitos como libertação, alteridade e tolerância, é importante instrumento para a discussão de temas como a eutanásia. O paciente em cuidados paliativos exclusivos é um vulnerável que se beneficia de uma abordagem ética crítica e que elabora juízos éticos baseados na ideia de proteção dos mais fragilizados.

É fundamental nestas situações de extrema dor familiar, que seja dedicado um tempo adequado para ouvir e analisar os pacientes terminais e suas famílias, sob uma leitura ética crítica, no sentido de valorizar a opinião dos principais atores direta e indiretamente envolvidos no processo de terminalidade da vida. A opinião de médicos e demais profissionais de saúde que lidam com pacientes terminais é igualmente de suma importância, embora esse tema específico não faça parte do escopo do presente estudo. 
Há, portanto, uma percepção de que a morte significa a cessação do sofrimento intenso vivido pela família e pelo paciente. Ora, tal percepção é muito importante para o debate sobre a regulamentação da eutanásia. Se a família entende a doença como terminal e se o paciente, sem chances de cura, sofre intensamente com ela, apesar dos cuidados paliativos dispensados, por que a abreviação da vida não poderia acontecer? Não seria esta abreviação, nestes casos, um imperativo moral?

Ocorre que a legislação brasileira não permite que um paciente terminal abrevie sua vida, evitando ser submetido a tratamentos fúteis que a prolonguem. Levando em consideração que a equipe de saúde não pode fazer mais nada, a não ser conviver com o sofrimento extremo de um vulnerável, o Estado não estaria aqui patrocinando uma forma de sofrimento desnecessário? Não seria este um Estado arbitrariamente "distanásico", ou seja, que apenas prorroga desnecessaria e dolorosamente uma vida sem esperança, na medida em que impede o único meio de cessar o sofrimento deste paciente?

Neste sentido, cabe inserir na discussão da regulamentação da eutanásia as noções de biopolítica, na medida em que o impedimento de uma morte desejada pelo indivíduo em situação de sofrimento inextinguível decorreria de uma técnica de biopoder excessivo, isto é, de controle excessivo do Estado sobre as populações. O corpo não seria nosso, mas do Estado, uma vez que não se pode decidir conforme o desejo individual.

Segundo Pessini (22), os procedimentos da medicina paliativa devem obedecer, entre outros, ao princípio ético do duplo efeito. Conforme este princípio, cabe garantir que haja razão proporcional entre, por exemplo, um tratamento para diminuir a dor e eventuais efeitos colaterais decorrentes deste tratamento, como a depressão respiratória e a dimuição da pressão arterial. Os efeitos negativos passam a ser tolerados se não houver solução mais eficaz para o tratamento do paciente. Neste caso, pode-se afirmar que a criminalização do eventual efeito negativo decorrente do direto da busca da analgesia, segundo o princípio do duplo efeito, prejudica a efetiva realização de cuidados paliativos em pacientes terminais. A equipe médica, amendrontada com as possibilidades de criminalização, tende a ser conservadora nos procedimentos de medicina paliativa, prejudicando o paciente já deveras vulnerabilizado. 
Com efeito, considerando as experiências aferidas no presente estudo e cotejadas com a análise comparativa feita entre a DUBDH e a legislação belga, pode-se inferir que a omissão por parte do Estado brasileiro ao não discutir ou não permitir um procedimento de eutanásia estaria em desacordo com princípios éticos previstos na DUBDH. Não oferecer ou conceder a um paciente terminal em cuidados paliativos o direito de abreviar seu sofrimento persistente fere alguns princípios da Declaração da Unesco, tais como o da dignidade humana, da vulnerabilidade humana e integridade pessoal, do respeito aos direitos humanos e ao consentimento, ao prolongar uma condição de vida intolerável, em alguns casos.

A vida é um direito fundamental, desde que haja percepção de qualidade de vida mínima, necessária para conferir dignidade ao ser humano(1). E tal percepção depende da moralidade das pessoas envolvidas diretamente na problemática. Neste sentido, é importante que as regulamentações da terminalidade da vida sejam adequadas à realidade de cada país, devendo ser analisadas com base na moralidade vigente, mas evitando que a moralidade majoritária entre a população se imponha sobre a moralidade de uma minoria vulnerável.

\section{Considerações Finais}

O direito de um paciente vulnerável de cessar um sofrimento incurável por meio da abreviação da vida terminal, conforme o que está regulamentado na legislação belga, não fere o disposto na Declaração Universal sobre Bioética e Direitos Humanos, mormente seus Artigos 3, 5, 6 e 8. Estão respeitados conceitos como autonomia, direitos humanos, dignidade humana, responsabilidade individual e consentimento individual.

É cada vez maior o número de pacientes sob cuidados paliativos exclusivos que pedem para morrer, porque continuam a vivenciar um sofrimento intenso. Assim, este tipo de situação deveria ser objeto de estudos adicionais para a adequada compreensão da realidade dos doentes brasileiros. 
Mesmo que os cuidados paliativos sejam ampliados e continuamente melhorados no sistema de saúde brasileiro, o que é indubitavelmente necessário, ainda assim parece-nos que restarão pacientes que, embora sob estes cuidados, manterão sofrimento intenso e desejarão ter seu sofrimento abreviado com procedimentos devidamente protegidos legalmente de eutanásia ou de suicídio assitido. Cabe ao Estado escutar estes pacientes e apontar soluções para este público muito específico.

Para discutir a regulamentação sobre o assunto, a bioética tem papel fundamental por fomentar o debate ético entre a sociedade, o Estado e os profissionais de saúde, incluindo essa discussão em âmbito nacional e internacional, uma vez que a aplicação da lei precisa levar em conta a opinião dos envolvidos em processo de terminalidade da vida.

A criação de um Conselho Nacional de Bioética, ou órgão correlato, a fim de assessorar os poderes da República brasileira acerca de questões éticas relacionadas com a saúde e a própria vida humana, poderia se configurar como um importante passo para regulamentar questões como a eutanásia e o suicídio assistido. Coube a um órgão semelhante, na Bélgica, a iniciativa para a criação da legislação sobre o assunto.

\section{Referências}

1. Warnock M, Macdonald E. Easeful death: is there a case for assisted dying? Oxford: Oxford University Press;2008.

2. Bélgica. Lei de 28 de maio de 2002. Loi relative à l'euthanasie $\mathrm{n}^{\mathrm{o}}$ 2002009590. Disponível em http://www.ejustice.just.fgov.be/cgi_loi/ change_lg.pl? language $=$ fr\&la $=F \& c n=2002052837 \&$ table_name $=$ loi (acesso $20 /$ set/2013).

3. Bélgica. Lei de 28 de fevereiro de 2014. Loi Modifiant la loi du 28 mai 2002 relative à l'euthanasie, en vue d'étendre l'euthanasie aux mineurs. Disponível em http://www.admd.be/legislation.html\#Loi soins palliatifs (acesso20/set/2013).

4. Kimsma GK. Death by request in The Netherlands: facts, the legal context and effects on physicians, patients and families. Med Health Care Philos. 2010 Nov; 13(4): 355-361.

5. Portail Santé. Fin de vie. Disponível em http://www.sante.public.lu/fr/ 
droits/fin-vie/index.html (acesso 15/nov/2014).

6. Cohen-Almagor R. Euthanasia in the Netherlands. New York: Kluwer Academic Pubishers ;2005.

7. Hurst S, Mauron A. Assisted suicide and euthanasia in Switzerland: allowing a role for non-physicians. BMJ. 2003 Feb 1; 326(7383): 271-273.

8. Oregon. Death with Dignity Act. 27 de outubro de 1997. Disponível em http://1.usa.gov/1XT4sAO (acesso 30/out 2014).

9. Tapajós A, Prado MM G V. Declaração Universal sobre Bioética e Direitos Humanos da Unesco. Tradução oficial Brasileira: Cátedra Unesco de Bioética da Universidade de Brasília 2005. Disponível em www.bioetica.catedraunesco.unb.br (acesso 15/nov/2013).

10. Brasil. Constituição da República Federativa do Brasil: Texto constitucional promulgado em 5 de outubro de 1988, com as alterações adotadas pelas Emendas Constitucionais $\mathrm{n}^{0}$ 1/92 a 53/2006 e pelas Emendas Constitucionais de Revisão n ${ }^{0} 1$ a 6/94. Brasília: Senado Federal, Subsecretaria de Edições Técnicas;2007.

11. Brasil. Novo Código Civil: Exposição de Motivos e Texto Sancionado. 2 ed. Senador Jorge Bornhausen. Brasília: Senado Federal;2006.

12. Brasil. Lei n. ${ }^{\circ} 8.080$, de 19 de setembro de 1990. Dispõe sobre as condições para a promoção, proteção e recuperação da saúde, a organização e o funcionamento dos serviços correspondentes e dá outras providências. Diário Oficial da União, Brasília, DF, 20 set. 1990. p.018055.

13. Brasil. Decreto Lei 2.848, de 07 de dezembro de 1940. Código Penal. Diário Oficial da União, Rio de Janeiro;31 dez. 1940.

14. Lima N, Luiz Inácio de. A legalização da eutanásia no Brasil. 2008. Disponível em http://www.egov.ufsc.br/portal/conteudo/ legaliza\%C3\%A7\%C3\%A3o-da-eutan\%C3\%A1sia-no-brasil (acesso em 20/dez/2013).

15. Xavier LSL. O Tratamento dado à Eutanásia nos últimos 30 anos no Brasil. 2002. Disponível em http://www.jurisway.org.br/v2/dhall. asp?id_dh=244 (acesso em 23/10/2013).

16. Brasil. Projeto de Lei do Senado $n^{0} 116$, de 2000. Exclui de ilicitude a ortotanásia. Altera o código penal. Disponível em http://www.senado. gov.br/atividade/Materia/detalhes.asp?p_cod_mate $=43807$ (acesso em 25/out/2013).

17. Conselho Ferderal de Medicina. Resolução CFM n ${ }^{\circ} 1.805$ de 2006. $\mathrm{Na}$ fase terminal de enfermidades graves e incuráveis é permitido ao médico limitar ou suspender procedimentos e tratamentos que prolonguem a vida do doente, garantindo-lhe os cuidados necessários para aliviar os sintomas que levam ao sofrimento, na perspectiva de uma assistência integral, respeitada a vontade do paciente ou de seu representante legal. Publicada no Diário Oficial da União, 28 nov. 2006, Seção I, pg. 169.

18. Lopes AC, Lima CAS, Santoro LF. Eutanásia, ortotanásia e distanásia: aspectos médicos e jurídicos. São Paulo: Atheneu;2011.

19. Brasil. Projeto de Lei da Câmara dos Deputados $n^{0}$ 6715, de 2009. Altera o Decreto-Lei n ${ }^{0}$ 2.848, de 7 de dezembro de 1940 (Código 
Penal), para excluir de ilicitude a ortotanásia. Disponível em http:// www.camara.gov.br/proposicoesWeb/prop_mostrarintegra;jsessionid $=6$ 87139B62AE4FD3187C64EF6448E4394.node2?codteor=728243\&filen ame $=$ PL $+6715 / 2009$ (acesso em 15/10/2013).

20. Minayo MCS. O desafio do conhecimento: pesquisa qualitativa em saúde. $11^{\circ}$ ed. São Paulo: Hucitec;2008.

21. Garrafa V. Da bioética de princípios a uma bioética interventiva. Rev. Bioética CFM 2005; 13(1):125-134.

22. Pessini L. Distanásia: até quando prolongar a vida? São Paulo: Edições Loyola;2007.

Recebido em: 22/07/2015 Aprovado em: 12/10/2015 